\title{
Risk factors for radiation-induced lung injury in patients with advanced non-small cell lung cancer: implication for treatment strategies
}

Sha Sha", Jigang Dong, Maoyu Wang, Ziyu Chen and Peng Gao

\begin{abstract}
Background: The radiation-induced lung injury (RILI) in patients with advanced non-small cell lung cancer (NSCLS) is very common in clinical settings; we aimed to evaluate the risk factors of RILI in NSCLS patients, to provide insights into the treatment of NSCLS.

Methods: NSCLC patients undergoing three-dimensional conformal radiotherapy (3D-CRT) in our hospital from June 1, 2018, to June 30, 2020, were included. The characteristics and treatments of RILI and non-RILI patients were analyzed. Logistic regression analyses were conducted to assess the risk factors of RILI in patients with NSCLC.

Results: A total of 126 NSCLC patients were included; the incidence of RILI in NSCLC patients was $35.71 \%$. There were significant differences in diabetes, smoke, chronic obstructive pulmonary disease (COPD), concurrent chemotherapy, radiotherapy dose, and planning target volume (PTV) between the RILI group and the non-RILI group (all $P<0.05$ ). Logistic regression analyses indicated that diabetes (OR 3.076, 95\%Cl 1.442 5.304), smoke (OR 2.745, 95\%Cl 1.288 4.613), COPD (OR 3.949, 95\%Cl 1.067 5.733), concurrent chemotherapy (OR 2.072, 95\%Cl 1.121 3.498), radiotherapy dose $\geq 60$ Gy (OR 3.841, 95\%Cl 1.932 5.362), and PTV $\geq 396$ (OR 1.247, 95\%Cl 1.107 1.746) were the independent risk factors of RILI in patients with NSCLC (all $P<0.05$ ).

Conclusions: RILI is commonly seen in NSCLS patients; early targeted measures are warranted for patients with those risk factors; future studies with larger sample sizes and different areas are needed to further elucidate the influencing factors of RILI in the treatment of NSCLS.
\end{abstract}

Keywords: Radiation, Lung injury, Non-small cell lung cancer, Treatment, Care

\section{Background}

Non-small cell lung cancer (NSCLC) is a common type of clinical lung cancer, which accounts for about about $40 \%$ of the total number of lung cancers $[1,2]$. Local radiotherapy treatment is an important treatment of NSCLC, and radiation-induced lung injury (RILI) is a common complication of thoracic radiation therapy.

\footnotetext{
* Correspondence: shasha_qjch@yeah.net

Department of Radiotherapy, Jiaozhou Central Hospital, No. 29 Xuzhou Road, Jiaozhou City, Qingdao 266300, China
}

Once RILI occurs, it is often irreversible and significant [3]. Therefore, the early prevention and treatment of RILI are crucial to improve the prognosis of patients.

Three-dimensional conformal radiotherapy (3D-CRT) refers to multiple beam irradiation technology that uses a series of different weights, different field shapes, and sizes to irradiate the target area from different directions [4-6]. A conformal lead that is consistent with the shape of the lesion is used to make the high-dose area consistent with the shape of the target area in three-

(c) The Author(s). 2021 Open Access This article is licensed under a Creative Commons Attribution 4.0 International License, which permits use, sharing, adaptation, distribution and reproduction in any medium or format, as long as you give appropriate credit to the original author(s) and the source, provide a link to the Creative Commons licence, and indicate if changes were made. The images or other third party material in this article are included in the article's Creative Commons licence, unless indicated otherwise in a credit line to the material. If material is not included in the article's Creative Commons licence and your intended use is not permitted by statutory regulation or exceeds the permitted use, you will need to obtain permission directly from the copyright holder. To view a copy of this licence, visit http://creativecommons.org/licenses/by/4.0/ The Creative Commons Public Domain Dedication waiver (http://creativecommons.org/publicdomain/zero/1.0/) applies to the data made available in this article, unless otherwise stated in a credit line to the data. 
dimensional space and at the same time reduce the dose of normal tissues around the target area [7, 8]. RILI is one of the main side effects of thoracic cancer radiotherapy. The clinical incidence of RILI is reported in previous studies to be 5.12 to $36.07 \%$, which can significantly affect the treatment and prognosis of patients [9-11]. Although 3D-CRT can reduce radiation damage to normal tissues through precise quantitative control of cancer radiation dose, the occurrence of RILI with clinical symptoms is still very common [12]. RILI patients have a series of non-specific respiratory symptoms due to severe lung injury, which will seriously affect the patient's quality of life [13-15]. How to predict and prevent the occurrence of RILI has become an urgent problem to be solved in radiotherapy [16]. Therefore, we aimed to evaluate the risk factors of RILI in NSCLC patients, to provide insights into the clinical prevention and treatment of RILI.

\section{Methods}

\section{Ethical considerations}

In this study, all methods were performed in accordance with the relevant guidelines and regulations. This present study had been checked and approved by the ethical committee of our hospital (approval number: DE180042), all the participants had been well-informed, and written informed consents had been obtained from all the included patients.

\section{Patients}

This study selected NSCLC patients who underwent 3DCRT in our hospital from June 1, 2018, to June 30, 2020, as study populations. The inclusion criteria of the patients were as follows: (1) patients were diagnosed with pathological examination as NSCLC [17, 18]; (2) age< 70 years old, (3) Karnofsky score $\geq 70$ points, (4) patients received 3D-CRT, and (5) the follow-up period after radiotherapy was $\geq 6$ months. The exclusion criteria for patients were as follows: (1) distant metastasis occurred during radiotherapy, (2) there were interruptions during radiotherapy $>1$ week, (3) surgery treatment was performed during radiotherapy, and (4) patients were unwilling to participant in this present study.

\section{D-CRT}

Gamma MEDx 100 (German) was used for the 3D-CRT. The patient was fixed with hydrolyzed plastic forming technology, and the arms are raised and crossed on the top of the forehead. The patient kept breathing calmly and performed a spiral CT scan, ranging from the midline of the neck to $3 \mathrm{~cm}$ below the diaphragm, including the whole lung tissue, with a thickness of $3 \mathrm{~mm}$. The positioning image was obtained, the $Z$ line value was approved, and the $\mathrm{X}, \mathrm{Y}$, and $\mathrm{Z}$ coordinates of the marked points on the patient's body surface. For the parameters and repeated positioning readings, we used bony markers that are not easy to move as the marking points on the body surface and transmitting the positioning images obtained from the positioning scan to the Curer 8.0 treatment planning system via the network. Target area delineation: we delineated the gross tumor volume (GTV) layer by layer under the lung window of the CT image after the 3D reconstruction, and the clinical target volume (CTV) was obtained by placing $6 \mathrm{~mm}$ of squamous cell carcinoma GTV. For adenocarcinoma, GTV was placed $8 \mathrm{~mm}$ to obtain CTV, and CTV was expanded by $5 \mathrm{~mm}$ to obtain the planned target volume (PTV). If the patient's lung function was poor or the CTV is large, the CTV should be manually modified according to the patient's lung function status and breathing amplitude. We appropriately increased the scope of the patient's upper and lower PTV extension up to 10 15 mm outside the CTV. The radiation therapy dose was $46 \sim 70$ Gy (the median dose is $60 \mathrm{~Gy}$ ), 5 times per week, 1.8 2.0 Gy per time. Normal tissue dose limits: spinal cord $D_{\max } \leq 45 \mathrm{~Gy}$, esophagus $\mathrm{D}_{\max } \leq 60 \mathrm{~Gy}$, lung $\mathrm{V}_{5} \leq 65 \%$, lung $\mathrm{V}_{20} \leq 25 \%$, lung $\mathrm{V}_{30} \leq 20 \%$.

\section{Chemotherapy}

The chemotherapy regimen used in our study was as follows: paclitaxel (Xinwei, Shanghai, S0190335) or docetaxel (Gynesier, German, C901241511) + cisplatin (Minhua, Shenzhen, W291101) or carboplatin (Huangchen, Zhengzhou, 1910418). The first-line regimen of intravenous infusion of paclitaxel $\left(135 \sim 175 \mathrm{mg} \mathrm{m}^{-2}\right)$ (day 1), docetaxel $\left(65 \sim 75 \mathrm{mg} \mathrm{m}^{-2}\right)$ (day 1), cisplatin (80$100 \mathrm{mg} \mathrm{m}^{-2}$ ) (days 2 and 3), and carboplatin (300-350 $\mathrm{mg} \mathrm{m}^{-2}$ ) (day 2). At $21-28$ days for 1 cycle, a total of 2 to 6 cycles were completed.

\section{Diagnostic criteria of RILI}

RILI toxicity was assessed with the Common Terminology Criteria for Adverse Events version 4.0, which was divided into 0 to 5 levels: grade $0-$ no obvious symptoms or signs change before and after treatment; grade $1-$ mild cough or shortness of breath after radiotherapy; grade 2-cough was persistent and requires medicine to relieve it and asthma after exercise; grade 3: severe cough, asthma, and shortness of breath were presented in the resting state, which could not be relieved by drugs, and the imaging examination revealed radiation pneumonia. Glucocorticoid therapy was effective; grade 4-dyspnea, oxygen, or assisted ventilation; and grade 5-patient death due to ventilatory failure and lung failure.

\section{Data collection}

Two authors collected the following personal characteristics and treatment data of patients: gender, age, body 
mass index (BMI), diabetes, hypertension, hyperlipidemia, smoke, chronic obstructive pulmonary disease (COPD), pathological type, concurrent chemotherapy, Karnofsky percent score (KPS), tumor staging, cancer size, radiotherapy dose (Gy), $V_{5}, V_{10}, V_{20}, V_{30}, M L D$, GTV, and PTV.

\section{Statistical analysis}

We used the SPSS 24.0 statistical software for statistical analysis. Enumeration data was expressed as cases and percentages, and the chi-square test was used for comparison between the groups; measurement data was expressed as mean \pm standard deviation, and the $t$ test was used for comparison between the groups. Logistic regression analyses were conducted to assess the risk factors of RILI in patients with NSCLC. $P<0.05$ indicates that the difference was statistically significant.

\section{Results}

The characteristics of included patients

A total of 126 NSCLC patients were included, of whom 45 patients had RILI; the incidence of RILI in NSCLC patients was $35.71 \%$. As presented in Table 1, there were significant differences in diabetes, smoke, COPD, concurrent chemotherapy, radiotherapy dose, and PTV between the RILI group and non-RILI group (all $P<0.05$ ). But no significant differences in gender, age, BMI, hypertension, hyperlipidemia, pathological type, KPS, tumor staging, cancer size, $\mathrm{V}_{5}, \mathrm{~V}_{10}, \mathrm{~V}_{20}, \mathrm{~V}_{30}$, MLD, and GTV between the RILI group and the non-RILI group were found (all $P>0.05$ ).

\section{Logistic regression analysis on the risk factors of RILI in patients with NSCLC}

The variable assignments of multivariate logistic regression were presented in Table 2. As indicated in Table 3, diabetes (OR 3.076, 95\%CI 1.442 5.304), smoke (OR

Table 1 The characteristics of included patients

\begin{tabular}{|c|c|c|c|c|}
\hline Variables & RILI group $(n=45)$ & Non-RILI group $(n=81)$ & $x^{2} / t$ & $P$ \\
\hline Male/female & $31 / 14$ & $48 / 33$ & 1.029 & 0.112 \\
\hline Age (years) & $61.01 \pm 8.52$ & $60.17 \pm 9.33$ & 4.381 & 0.065 \\
\hline $\mathrm{BMI}\left(\mathrm{kg} / \mathrm{m}^{2}\right)$ & $22.27 \pm 4.15$ & $22.09 \pm 3.98$ & 3.424 & 0.082 \\
\hline Diabetes & $24(53.33 \%)$ & $20(24.69 \%)$ & 1.187 & 0.013 \\
\hline Hypertension & $25(55.56 \%)$ & $44(54.32 \%)$ & 1.272 & 0.104 \\
\hline Hyperlipidemia & $10(22.22 \%)$ & $16(19.75 \%)$ & 1.489 & 0.076 \\
\hline Smoke & $31(68.89 \%)$ & $24(29.63 \%)$ & 1.233 & 0.014 \\
\hline COPD & $18(40 \%)$ & $22(27.16 \%)$ & 1.504 & 0.046 \\
\hline \multicolumn{5}{|l|}{ Pathological type } \\
\hline Squamous cell carcinoma & $32(71.11 \%)$ & $58(71.61 \%)$ & 1.127 & 0.088 \\
\hline Adenocarcinoma & $13(28.89 \%)$ & $23(28.39 \%)$ & & \\
\hline Concurrent chemotherapy & $39(86.67 \%)$ & $61(75.31 \%)$ & 1.231 & 0.039 \\
\hline KPS & $84.43 \pm 12.72$ & $82.76 \pm 11.23$ & 1.107 & 0.092 \\
\hline \multicolumn{5}{|l|}{ Tumor staging } \\
\hline IIla & $24(53.33 \%)$ & $44(54.32 \%)$ & 1.145 & 0.106 \\
\hline $111 \mathrm{~b}$ & $22(48.89 \%)$ & $37(45.68 \%)$ & & \\
\hline Cancer size $(\mathrm{cm})$ & $5.88 \pm 3.26$ & $5.65 \pm 2.64$ & 1.230 & 0.085 \\
\hline Radiotherapy dose (Gy) & $63.75 \pm 11.32$ & $52.48 \pm 10.66$ & 9.277 & 0.001 \\
\hline$V_{5}$ & $54.44 \pm 11.68$ & $53.26 \pm 12.42$ & 11.207 & 0.073 \\
\hline$V_{10}$ & $32.76 \pm 8.01$ & $29.19 \pm 9.54$ & 8.021 & 0.081 \\
\hline$V_{20}$ & $22.12 \pm 5.37$ & $21.35 \pm 5.95$ & 9.101 & 0.089 \\
\hline$V_{30}$ & $12.31 \pm 4.98$ & $11.93 \pm 4.17$ & 4.116 & 0.105 \\
\hline MLD & $949.59 \pm 242.83$ & $898.91 \pm 282.44$ & 77.174 & 0.059 \\
\hline GTV & $169.05 \pm 52.18$ & $149.77 \pm 61.72$ & 18.101 & 0.091 \\
\hline PTV & $472.34 \pm 69.64$ & $321.58 \pm 79.84$ & 53.374 & 0.011 \\
\hline
\end{tabular}

Note: The percentage of the lung volume that received more than a certain dose of the total lung volume was recorded as V5 ( $\leq 65 \%), \mathrm{V} 10(\leq 20 \%), \mathrm{V} 20(\leq 25 \%)$, and V30 $(\leq 20 \%)$ accordingly

$R I L I$ radiation-induced lung injury, $B M I$ body mass index, COPD chronic obstructive pulmonary disease, $M L D$ mean lung dose, GTV gross target volume, PTV planning target volume 
2.745, 95\%CI 1.288 4.613), COPD (OR 3.949, 95\%CI 1.067 5.733), concurrent chemotherapy (OR 2.072, 95\%CI 1.121 3.498), radiotherapy dose $\geq 60$ Gy (OR 3.841, 95\%CI 1.932 5.362), and PTV $\geq 396$ (OR 1.247, $95 \%$ CI 1.107 1.746) were the independent risk factors of RILI in patients with NSCLC (all $P<0.05$ ).

\section{Discussions}

RILI is one of the important toxic reactions of radiotherapy in the treatment of thoracic tumors. RILI often appears during radiotherapy to 3 months after radiotherapy $[19,20]$. It usually manifests as dry cough, fever, shortness of breath, etc. In severe cases, severe breathing difficulties, respiratory failure, and even death can occur. Numerous studies [21-24] have shown that clinical factors, therapeutic factors, metrological factors, and biological factors are closely related to the occurrence of RILI. The results of this study have shown that diabetes, smoke, COPD, concurrent chemotherapy, radiotherapy dose $\geq 60 \mathrm{~Gy}$, and PTV $\geq 396$ were the independent risk factors of RILI in patients with NSCLC; special attentions and early interventions are needed for NSCLC patients with those risk factors.

In this study, the incidence of RILI in NSCLC patients that received 3D-CRT was $35.71 \%$, which is consistent with several previous studies $[25,26]$. It has been found that the incidence of RILI in patients receiving concurrent chemotherapy is $63.17 \%$, while the incidence of RILI in patients who did not undergo chemotherapy is only $16 \%$, and the incidence of RILI is higher in patients who received paclitaxel + carboplatin [27-30]. We have found that whether to receive concurrent chemotherapy is significantly related to the incidence of RILI, which may be associated with the fact that patients undergoing chemotherapy treatment are prone to lower immune levels and higher organ sensitivity. It has been found that MLD and the percentage of the total lung volume (lung $\mathrm{V}_{5}, \mathrm{~V}_{10}, \mathrm{~V}_{20}, \mathrm{~V}_{30}, \mathrm{~V}_{40}, \mathrm{~V}_{50}$, and $\mathrm{V}_{60}$ ) of the lung volume that received more than a certain dose of irradiation are independent risk factors for RP after 3D-CRT treatment

Table 2 The variable assignment of multivariate logistic regression

\begin{tabular}{lll}
\hline Factors & Variables & Assignment \\
\hline RILI & Y & Yes $=1$, no $=2$ \\
Diabetes & $X_{1}$ & Yes $=1$, No $=2$ \\
Smoke & $X_{2}$ & Yes $=1$, No $=2$ \\
COPD & $X_{3}$ & Yes $=1$, No $=2$ \\
Concurrent chemotherapy & $X_{4}$ & Yes $=1$, No $=2$ \\
Radiotherapy dose (Gy) & $X_{5}$ & $\geq 56=1,<56=2$ \\
PTV & $X_{6}$ & $\geq 396=1,<396=2$ \\
\hline
\end{tabular}

$R I L /$ radiation-induced lung injury, COPD chronic obstructive pulmonary disease, PTV planning target volume
Table 3 The logistic regression analysis on the risk factors of RILI in patients with NSCLC

\begin{tabular}{llllll}
\hline Variables & $\boldsymbol{\beta}$ & $\mathbf{S}^{-} \mathbf{x}$ & $\mathbf{O R}$ & $\mathbf{9 5 \%} \mathbf{C I}$ & $\mathbf{p}$ \\
\hline Diabetes & 0.173 & 0.227 & 3.076 & $1.442 \sim 5.304$ & 0.019 \\
Smoke & 0.129 & 0.214 & 2.745 & $1.288 \sim 4.613$ & 0.033 \\
COPD & 0.103 & 0.151 & 3.949 & $1.067 \sim 5.733$ & 0.007 \\
Concurrent chemotherapy & 0.124 & 0.139 & 2.072 & $1.121 \sim 3.498$ & 0.038 \\
Radiotherapy dose $\geq 60$ Gy & 0.191 & 0.122 & 3.841 & $1.932 \sim 5.362$ & 0.025 \\
PTV $\geq 396$ & 0.131 & 0.107 & 1.247 & $1.107 \sim 1.746$ & 0.042
\end{tabular}

COPD chronic obstructive pulmonary disease, $P T V$ planning target volume

of NSCLC [31-33]. Besides, it has been reported that MLD, $V_{20}, V_{30}, V_{40}$, and $V_{50}$ have predictive significance for RILI in NSCLC patients treated with radiotherapy and chemotherapy [34].

Diabetes, smoking, and COPD are risk factors related to RILI. This study shows that smoking is a risk factor for RILI. Some studies $[14,35,36]$ have shown that smoking is an independent protective factor for RP. It is considered that the hypoxia and immunosuppression caused by smoking may be related to the increased lung tolerance of smoking patients [37]. Studies [30, 38] have pointed out that factors such as smoking, COPD, and ventilatory dysfunction can increase the risk of RILI. It is recommended that lung diffusion function be tested before radiotherapy to evaluate lung function status [39]. Therefore, in radiotherapy, attention should be paid to the exposure volume and exposure dose [40]. At the same time, if the patient has diabetes, smoking, COPD, concurrent chemotherapy, and radiotherapy, the total dose should be optimized and preventive measures should be taken to reduce the occurrence of RILI [41]. Previous studies $[42,43]$ have shown that complications such as chronic obstructive pulmonary disease and ventilatory dysfunction caused by smoking can increase the risk of lung injury. It is recommended that the lung diffusion function be tested before radiotherapy to evaluate the status of lung function.

This study also has certain shortcomings that must be considered. Firstly, the sample size of this study, especially the number of cases in the RILI group, was small, so the statistical efficiency might be underpowered to detect the potential difference. Secondly, given the limited data, we could not do further subgroup analysis on the severity of RILI. Thirdly, radiation-induced lung injuries can also appear after 3 months, limited by collected data; we only analyzed the radiation-induced lung injuries within 3 months; future studies with longer follow-up are needed. Besides, there may be certain differences in radiotherapy doses and schedules in various hospitals, and future large-sample multi-center studies are needed to further analyze and explore related influencing factors of RILI in NSCLC patients. 


\section{Conclusions}

In conclusion, we have found that the incidence of RILI in NSCLC patients is $35.71 \%$, and for patients with diabetes, smoke, COPD, concurrent chemotherapy, radiotherapy dose $\geq 60 \mathrm{~Gy}$, and PTV $\geq 396$, they may have higher risk factors of RILI; early alert and preventative measures are needed for those patients. At present, the prevention and treatment of RILI are still a difficult problem to solve, and its occurrence is related to many factors. It must be noted that our cohort may be exceedingly small heterogenous that cannot be applied to a larger cohort limited by the small sample size. The clinical value of the observation indicators in this study needs to be further verified in future studies. Moreover, the mechanism of RILI and related influencing factors also needs to be explored in the future.

\section{Abbreviations}

RILI: Radiation-induced lung injury; NSCLS: Non-small cell lung cancer; COPD: Chronic obstructive pulmonary disease; PTV: Planning target volume; 3D-CRT: Three-dimensional conformal radiotherapy; GTV: Gross tumor volume; CTV: Clinical target volume; BMl: Body mass index; KPS: Karnofsky percent score

\section{Acknowledgements}

None.

\section{Authors' contributions}

SS designed the research. JD, MW, ZC, and PG conducted the research. SS, $\mathrm{JD}$, and MW analyzed the data. SS wrote the first draft of the manuscript. SS had primary responsibility for the final content. All authors read and approved the final manuscript

\section{Funding}

None.

\section{Availability of data and materials}

All data generated or analyzed during this study are included in this published article.

\section{Declarations}

\section{Ethics approval and consent to participate}

In this study, all methods were performed in accordance with the relevant guidelines and regulations. This present study had been checked and approved by the ethical committee of our hospital (approval number: DE180042), all the participants had been well-informed, and written informed consents had been obtained from all the included patients.

\section{Consent for publication}

Not applicable.

\section{Competing interests}

The authors declare that they have no competing interests.

Received: 8 April 2021 Accepted: 25 June 2021

Published online: 16 July 2021

\section{References}

1. Ye Z, Huang Y, Ke J, Zhu X, Leng S, Luo H. Breakthrough in targeted therapy for non-small cell lung cancer. Biomed Pharmacother. 2021;133: 111079. https://doi.org/10.1016/j.biopha.2020.111079.

2. $\quad$ Feng $L$, Wang $Z$, Jing $L$, Zhou $Z$, Shi $S$, Deng $R$, et al. Recombinant human endostatin combined with chemotherapy for advanced squamous cell lung cancer: a meta-analysis. World J Surg Oncol. 2021;19(1):64. https://doi.org/1 $0.1186 / s 12957-021-02161-1$.
3. Bernchou U, Christiansen RL, Asmussen JT, Schytte T, Hansen O, Brink C. Extent and computed tomography appearance of early radiation induced lung injury for non-small cell lung cancer. Radiother Oncol. 2017;123(1):938. https://doi.org/10.1016/j.radonc.2017.02.001

4. Wei $X$, Jiang $Y$, Zhang $X$, Feng S, Zhou B, Ye X, et al. Neoadjuvant threedimensional conformal radiotherapy for resectable hepatocellular carcinoma with portal vein tumor thrombus: a randomized, open-label, multicenter controlled study. J Clin Oncol. 2019;37(24):2141-51. https://doi.org/10.1200/ JCO.18.02184.

5. Hirose TA, Arimura H, Ninomiya K, Yoshitake T, Fukunaga Jl, Shioyama Y. Radiomic prediction of radiation pneumonitis on pretreatment planning computed tomography images prior to lung cancer stereotactic body radiation therapy. Sci Rep. 2020;10(1):20424. https://doi.org/10.1038/s41598020-77552-7.

6. Farr KP, Khalil AA, Grau C. Patient-reported lung symptoms and quality of life before and after radiation therapy for non-small cell lung cancer: correlation with radiation pneumonitis and functional imaging. Acta Oncol. 2019;58(10):1523-7. https://doi.org/10.1080/0284186X.2019.1634835.

7. Jirkovska M, Novak T, Malinova B, Lohynska R. Three-dimensional conformal radiotherapy versus intensity modulated radiotherapy with simultaneous integrated boost in the treatment of locally advanced head and neck carcinoma. Neoplasma. 2019;66(5):830-8. https://doi.org/10.4149/neo_201 8 181209N941.

8. Sukari A, Nagasaka M, Alhasan R, Patel D, Wozniak A, Ramchandren R, et al. Cancer site and adverse events induced by immune checkpoint inhibitors: a retrospective analysis of real-life experience at a single institution. Anticancer Res. 2019;39(2):781-90. https://doi.org/10.21873/anticanres.13175.

9. Peng F, Stanton P, Bi N, Kong F. Dose-related changes for lung ventilation and perfusion and prediction for radiation-induced lung injury during the course of radiotherapy in patients with non-small cell lung cancer. Pract Radiat Oncol. 2013;3(2 Suppl 1):S26. https://doi.org/10.1016/j.prro.2013.01. 091.

10. Wang D, Sun J, Zhu J, Li X, Zhen Y, Sui S. Functional dosimetric metrics for predicting radiation-induced lung injury in non-small cell lung cancer patients treated with chemoradiotherapy. Radiat Oncol. 2012;7(1):69. https:// doi.org/10.1186/1748-717X-7-69.

11. Zhong L, Suo J, Wang $Y$, Han J, Zhou H, Wei H, et al. Prognosis of limitedstage small cell lung cancer with comprehensive treatment including radical resection. World J Surg Oncol. 2020;18(1):27. https://doi.org/10.1186/ s12957-020-1807-1.

12. Itamura H, Ohguri T, Yahara K, Nakahara S, Kakinouchi S, Morisaki T, et al. Pembrolizumab-induced radiation recall pneumonitis after the resolution of typical asymptomatic radiation pneumonitis. J UOEH. 2020;42(3):261-6. https://doi.org/10.7888/juoeh.42.261.

13. Shi L, He Y, Yuan Z, Benedict S, Valicenti R, Qiu J, et al. Radiomics for response and outcome assessment for non-small cell lung cancer. Technol Cancer Res Treat. 2018;17:1533033818782788.

14. Palma G, Monti S, Thor M, Rimner A, Deasy JO, Cella L. Spatial signature of dose patterns associated with acute radiation-induced lung damage in lung cancer patients treated with stereotactic body radiation therapy. Phys Med Biol. 2019;64(15):155006. https://doi.org/10.1088/1361-6560/ab2e16.

15. Li YQ, Zheng Z, Liu QX, Lu X, Zhou D, Zhang J, et al. Moesin as a prognostic indicator of lung adenocarcinoma improves prognosis by enhancing immune lymphocyte infiltration. World J Surg Oncol. 2021;19(1):109. https:// doi.org/10.1186/s12957-021-02229-y.

16. Chang SC, Lai YC, Hung JC, Chang CY. Oral glutamine supplements reduce concurrent chemoradiotherapy-induced esophagitis in patients with advanced non-small cell lung cancer. Medicine (Baltimore). 2019;98(8): e14463. https://doi.org/10.1097/MD.0000000000014463.

17. Duma N, Santana-Davila R, Molina JR. Non-small cell lung cancer: epidemiology, screening, diagnosis, and treatment. Mayo Clin Proc. 2019; 94(8):1623-40. https://doi.org/10.1016/j.mayocp.2019.01.013.

18. Reck M, Rabe KF. Precision diagnosis and treatment for advanced nonsmall-cell lung cancer. N Engl J Med. 2017;377(9):849-61. https://doi.org/1 0.1056/NEJMra1703413.

19. Jahangiri $P$, Pournazari $K$, Torigian DA, Werner TJ, Swisher-McClure $S$, Simone CB 2nd, et al. A prospective study of the feasibility of FDG-PET/CT imaging to quantify radiation-induced lung inflammation in locally advanced non-small cell lung cancer patients receiving proton or photon radiotherapy. Eur J Nucl Med Mol Imaging. 2019;46(1):206-16. https://doi. org/10.1007/s00259-018-4154-5. 
20. Hanaoka J, Yoden M, Hayashi K, Shiratori T, Okamoto K, Kaku R, et al. Dynamic perfusion digital radiography for predicting pulmonary function after lung cancer resection. World J Surg Oncol. 2021;19(1):43. https://doi. org/10.1186/s12957-021-02158-w.

21. Li Q, Liu Y, Su B, Zhao H, Lin Q, Zhu Y, et al. The CT appearance pattern of radiation-induced lung injury and tumor recurrence after stereotactic body radiation therapy in early stage non-small cell lung cancer. Transl Lung Cancer Res. 2020;9(3):713-21. https://doi.org/10.21037/tlcr-20-609.

22. Mehta V. Open label multicenter trial of subcutaneous amifostine (Ethyol) in the prevention of radiation induced esophagitis and pneumonitis in patients with measurable, unresectable non-small cell lung cancer. Semin Oncol. 2004;31(6 Suppl 18):42-6. https://doi.org/10.1053/j.seminoncol.2 004.12 .011$.

23. Chen J, Lu JJ, Ma N, Zhao J, Chen C, Fan M, et al. Early stage non-small cell lung cancer treated with pencil beam scanning particle therapy: retrospective analysis of early results on safety and efficacy. Radiat Oncol. 2019;14(1):16. https://doi.org/10.1186/s13014-019-1216-1.

24. Wu LL, Lai JJ, Liu X, Huang YY, Lin P, Long H, et al. Association between number of dissected lymph nodes and survival in stage IA non-small cell lung cancer: a propensity score matching analysis. World J Surg Oncol. 2020;18(1):322. https://doi.org/10.1186/s12957-020-02090-5.

25. Zhang H, Jiang T, Yu H, Lu H, Zhao Y, Zhang Y, et al. Polyene phosphatidylcholine protects against radiation induced tissue injury without affecting radiotherapeutic efficacy in lung cancer. Am J Cancer Res. 2019; 9(6):1091-103.

26. Moran A, Daly ME, Yip SSF, Yamamoto T. Radiomics-based assessment of radiation-induced lung injury after stereotactic body radiotherapy. Clin Lung Cancer. 2017;18(6):e425-31. https://doi.org/10.1016/j.cllc.2017.05.014.

27. Torre-Bouscoulet L, Munoz-Montano WR, Martinez-Briseno D, Lozano-Ruiz FJ, Fernandez-Plata R, Beck-Magana JA, et al. Abnormal pulmonary function tests predict the development of radiation-induced pneumonitis in advanced non-small cell lung cancer. Respir Res. 2018;19(1):72. https://doi. org/10.1186/s12931-018-0775-2.

28. Itonaga T, Sugahara S, Mikami R, Saito T, Yamada T, Kurooka M, et al. Evaluation of the relationship between the range of radiation-induced lung injury on CT images after IMRT for stage I lung cancer and dosimetric parameters. Ann Med. 2021;53(1):267-73. https://doi.org/10.1080/07853890.2 020.1869297.

29. Sheng $Y$, Chen $K$, Jiang $W$, Wu Z, Zhang $W$, Jing $H$, et al. PD-1 restrains IL$17 \mathrm{~A}$ production from gammadelta $T$ cells to modulate acute radiationinduced lung injury. Transl Lung Cancer Res. 2021;10(2):685-98. https://doi. org/10.21037/t|cr-20-838.

30. Menoux I, Antoni D, Mazzara C, Labani A, Charloux A, Quoix E, et al. Radiation-induced lung toxicity predictors: retrospective analysis of 90 patients treated with stereotactic body radiation therapy for stage I nonsmall-cell lung carcinoma. Cancer Radiother. 2020;24(2):120-7. https://doi. org/10.1016/j.canrad.2019.11.003.

31. Yue J, Shi Q, Xu T, Jeter M, Chen TY, Komaki R, et al. Patient-reported lung symptoms as an early signal of impending radiation pneumonitis in patients with non-small cell lung cancer treated with chemoradiation: an observational study. Qual Life Res. 2018;27(6):1563-70. https://doi.org/10.1 007/s11136-018-1834-3.

32. Wang W, Men Y, Wang J, Zhou Z, Chen D, Xiao Z, et al. Postoperative radiotherapy is effective in improving survival of patients with stage plll-N2 non-small-cell lung cancer after pneumonectomy. BMC Cancer. 2019;19(1): 478. https://doi.org/10.1186/s12885-019-5692-3.

33. Zhou Y, Yan T, Zhou X, Cao P, Luo C, Zhou L, et al. Acute severe radiation pneumonitis among non-small cell lung cancer (NSCLC) patients with moderate pulmonary dysfunction receiving definitive concurrent chemoradiotherapy: impact of pre-treatment pulmonary function parameters. Strahlenther Onkol. 2020;196(6):505-14. https://doi.org/10.1007/ s00066-019-01552-4

34. Xiao L, Yang G, Chen J, Yang Y, Meng X, Wang X, et al. Comparison of predictive powers of functional and anatomic dosimetric parameters for radiation-induced lung toxicity in locally advanced non-small cell lung cancer. Radiother Oncol. 2018;129(2):242-8. https://doi.org/10.1016/j.ra donc.2018.09.005

35. Nakajima M, Yamamoto N, Hayashi K, Karube M, Ebner DK, Takahashi W, et al. Carbon-ion radiotherapy for non-small cell lung cancer with interstitial lung disease: a retrospective analysis. Radiat Oncol. 2017;12(1):144. https:// doi.org/10.1186/s13014-017-0881-1.
36. Menoux I, Le Fevre C, Noel G, Antoni D. Radiation-induced lung toxicity predictors after stereotactic radiation therapy for non-small cell lung carcinoma stage I. Cancer Radiother. 2018;22(8):826-38. https://doi.org/10.1 016/j.canrad.2017.12.007.

37. Ireland RH, Din OS, Swinscoe JA, Woodhouse N, van Beek EJ, Wild JM, et al. Detection of radiation-induced lung injury in non-small cell lung cancer patients using hyperpolarized helium-3 magnetic resonance imaging. Radiother Oncol. 2010;97(2):244-8. https://doi.org/10.1016/j.radonc.2010.07. 013.

38. Kalman NS, Hugo GD, Mahon RN, Deng X, Mukhopadhyay ND, Weiss E. Diabetes mellitus and radiation induced lung injury after thoracic stereotactic body radiotherapy. Radiother Oncol. 2018;129(2):270-6. https:// doi.org/10.1016/j.radonc.2018.08.024.

39. Liu Y, Zhu Y, Wu R, Hu M, Zhang L, Lin Q, et al. Stereotactic body radiotherapy for early stage non-small cell lung cancer in patients with subclinical interstitial lung disease. Transl Lung Cancer Res. 2020;9(6):232836. https://doi.org/10.21037/tlcr-20-1050.

40. Nobashi TW, Nishimoto Y, Kawata Y, Yutani H, Nakamura M, Tsuji Y, et al. Clinical and radiological features of immune checkpoint inhibitor-related pneumonitis in lung cancer and non-lung cancers. Br J Radiol. 2020; 93(1115):20200409. https://doi.org/10.1259/bjr.20200409.

41. Bousabarah K, Temming S, Hoevels M, Borggrefe J, Baus WW, Ruess D, et al. Radiomic analysis of planning computed tomograms for predicting radiation-induced lung injury and outcome in lung cancer patients treated with robotic stereotactic body radiation therapy. Strahlenther Onkol. 2019; 195(9):830-42. https://doi.org/10.1007/s00066-019-01452-7.

42. Evison M, Barrett E, Cheng A, Mulla A, Walls G, Johnston D, et al. Predicting the risk of disease recurrence and death following curative-intent radiotherapy for non-small cell lung cancer: the development and validation of two scoring systems from a large multicentre UK cohort. Clin Oncol (R Coll Radiol). 2021;33(3):145-54. https://doi.org/10.1016/j.clon.2020. 09.001 .

43. Shintani T, Kishi N, Matsuo Y, Ogura M, Mitsuyoshi T, Araki N, et al. Incidence and risk factors of symptomatic radiation pneumonitis in nonsmall-cell lung cancer patients treated with concurrent chemoradiotherapy and consolidation durvalumab. Clin Lung Cancer. 2021. https://doi.org/10.1 016/j.cllc.2021.01.017.

\section{Publisher's Note}

Springer Nature remains neutral with regard to jurisdictional claims in published maps and institutional affiliations.

Ready to submit your research? Choose BMC and benefit from:

- fast, convenient online submission

- thorough peer review by experienced researchers in your field

- rapid publication on acceptance

- support for research data, including large and complex data types

- gold Open Access which fosters wider collaboration and increased citations

- maximum visibility for your research: over $100 \mathrm{M}$ website views per year

At $\mathrm{BMC}$, research is always in progress.

Learn more biomedcentral.com/submissions 